\title{
Comment
}

\section{Psicologia e Educação Infantil: Desafios atuais}

\author{
Francimária Sousa Santos Silvana ${ }^{1}$;islene Farias de Oliveira ${ }^{2}$
}

Resumo: O presente estudo é fruto de análise crítica da atual situação escolar infantil pública no que concerne ao acompanhamento e presença do psicólogo em sua equipe permanente. As relações estabelecidas entre a psicologia e o espaço escolar emergem como alicerce para desenvolver e ampliar as discussões aqui afloradas. Enquanto objetivos desta pesquisa encontram-se: identificar as atribuições do psicólogo escolar, discutir acerca da necessidade de sua inclusão e os possíveis fatores que ora implicam na sua ausência de forma mais incisiva e eficaz no contexto educacional. Este trabalho caracteriza-se metodologicamente uma pesquisa de cunho bibliográfico. Evoluindo em suas categorias desde a escolha e organização do referencial, a sua consequente exploração, finalizando com os resultados interpretações e inferências. É importante ressaltar o quanto o profissional da psicologia se faz necessário na mediação das relações existentes neste espaço educacional. A ausência deste profissional torna-se preocupante, o que atribui a esta pesquisa um caráter de relevância por suscitar questionamentos e proposições importantes a esta temática, permitindo considerações e contribuições futuras de profissionais afins.

Palavras-chave: Educação Infantil; Inserção do psicólogo; rede pública de ensino.

\section{Psychology and Early Childhood Education: Current Challenges}

\begin{abstract}
The present study is the result of a critical analysis of the current public school situation in relation to the psychologist 's attendance and presence in his permanent team. The established relations between psychology and the school space emerge as a foundation to develop and broaden the discussions that emerge here. While the objectives of this research are: to identify the attributions of the school psychologist, to discuss about the necessity of their inclusion and the possible factors that now imply in their absence in a more incisive and effective way in the educational context. This work is characterized methodologically a research of bibliographic character. Evolving in its categories since the choice and organization of the referential, its consequent exploration, ending with the results interpretations and inferences. It is important to emphasize how much the professional of psychology becomes necessary in the mediation of the existing relationships in this educational space. The absence of this professional becomes worrying, which attributes to this research a character of relevance for raising important questions and propositions to this theme, allowing for future considerations and contributions of related professionals.
\end{abstract}

Keywords: Child Education; Insertion of the psychologist; Public school system.

${ }^{1}$ Especialista em Geografia Geral, Mestranda em Ciências da Educação, graduada em Geografia pela Faculdade de Formação de professores de Araripina-PE. Email: francisousa87@gmail.com

${ }^{2}$ Doutora em Psicologia Social e Pós-doutorado em Ciências da Saúde. Professora Associada da Universidade Federal do Cariri - UFCA.

E-mail: gislenefarias@gmail.com. 
Id on Line Revista Multidisciplinar e de Psicologia

Id on Line Multidisciplinary and Psycology Journal

\section{Introdução}

A partir da necessidade de compreender melhor as relações existentes entre a psicologia e o contexto escolar, vê-se no âmbito educacional a possibilidade de abordar questões interessantes e pertinentes, emergindo, pois como cerne destas discussões, a inserção do profissional da psicologia da rede pública de educação infantil.

É sabido que este segmento da educação não conta com a atuação do profissional de psicologia em suas equipes, e por algumas vezes encontra-se substituído por outros profissionais, como se o seu fazer pudesse ser fácil e simplesmente desenvolvido por outrem. Esta ocorrência em grande parte se dá pelo desconhecimento do que é realmente intrínseco ao psicólogo e sua atuação.

Focaliza-se então a presente pesquisa na educação infantil, por ser a infância o momento em que a criança passara a interagir com outros sujeitos e consolidar suas primeiras relações para além do seio familiar. Essas reações pessoais ajudam a firmar sua individualidade e a reconhecer seus próprios sentimentos. Começa, assim, sua integração com o universo da comunicação social e a definição de sua identidade (MOREIRA , 1996) .

Desta forma, com a proposta de atender á importância, necessidade e prática da psicologia neste espaço, com ênfase na rede pública de educação, é que se faz necessário um estudo mais aprimorado e critico em torno desta temática. Visto a lacuna, por ora existente, da atuação do psicólogo na escola pública; nesta fase tão expressiva e complexa á criança que marcara o inicio das primeiras amizades fora do lar; permitindo-a praticar uma série de habilidades sociais (BEE, 2003).

Pretende-se inicialmente, abordar a noção de Educação Infantil bem como suas implicações na vida não apenas escolar da criança, mas familiar e social.

Nesta discussão, também se englobam outras questões não menos pertinentes como a importância do lucido; a noção de educação nas creches e a visão que estas despertaram ao longo dos tempos. E finalizando este tema, os fatores essenciais ao ambiente escolar a fim de contribuir para o bom desenvolvimento das crianças.

Em seguida, traz-se para também fundamentar a cerne deste trabalho, o processo histórico de inserção do psicólogo na educação brasileira; com o intuito de proporcionar um 
Id on Line Revista Multidisciplinar e de Psicologia

Id on Line Multidisciplinary and Psycology Journal

melhor entendimento sobre a chegada deste profissional na realidade escolar e compreender possíveis heranças históricas que acompanharam a noção do fazer do psicólogo.

Com tema de encerramento a ser abordado neste trabalho, tem-se o fazer do psicólogo no contexto educacional e sua importância.

Sobre o fazer do psicólogo, Moreira (1996) versa que o caminho proposto pela psicologia conduz á autonomia; ao encontro social e vivencia da cidadania, fornecendo subsídios para o desenvolvimento de uma consciência pessoal e social.

As atribuições feitas á psicologia como possuidora de um olhar diferenciado e necessário aos cuidados da criança, mais especificamente inseridas no contexto escolar.

Buscando a convicção do psicólogo na educação infantil pública como um imperativo, também será discutido o desejo de concretizar legalmente a inserção deste profissional na educação básica, pleiteado pelo Conselho Federal de Psicologia juntamente como Conselho Federal de Assistência Social que também anseia pela regulamentação de seus profissionais neste contexto educacional.

O referido trabalho caracteriza-se por ater-se a uma metodologia de pesquisa bibliográfica, de natureza qualitativa, visto que, dentre os tipos de pesquisa existentes é a pesquisa qualitativa que melhor encaixou-se á proposta deste estudo.

\section{Educação Infantil}

A noção de infância é um conceito ainda recente quando se considera a historia da ciência. Essa concepção o tratamento que a sociedade dispensava as crianças. Elas recebiam cuidados especiais até os sete anos de idade. Depois ingressavam na comunidade dos adultos desenvolviam as mesmas atividades que eles (CÓRIA SABINI, 1993).

A partir do século XIX, a noção de infância foi evoluindo, e as crianças começaram o processo de serem percebidas não mais como pequenos adultos, ou adultos em miniatura (ARIÉ, 2006), e a preocupação com a educação destes pequenos foi emergindo.

Na contemporaneidade o tema educação infantil é uma constante. Nunca se falou tanto em educação como agora. A quantidade de livros traduzidos e produzidos no pais impressiona, 
assim como o número de pesquisas, tratados, dicionários e textos de ensino e aprendizagem (ANTUNES, 2002).

Atualmente, considera-se como Educação Infantil, o período de vida escolar em que se atende, pedagogicamente, crianças com idade entre 0 e 6 anos, sendo o atendimento de 0 a 3 anos feito pelas creches e de 4 a 6 anos pela pré-escola (LDB).

Segundo o art. 29 da Lei de Diretrizes e Bases da Educação Nacional (1996):

A educação infantil, primeira etapa de educação básica, tem como finalidade o desenvolvimento integral da criança até seis anos de idade, em seus aspectos físico, psicólogo, intelectual e social, complementando a ação da família e da comunidade (LDB, 1996).

Na Educação Infantil as crianças são estimuladas através de atividades lúdicas e jogos, a exercitar suas capacidades motoras, fazer descobertas, e iniciar o processo de letramento.

\begin{abstract}
Os cuidados ministrados na creche e na pré-escola não se reduzem ao atendimento de necessidade físicas das crianças, deixando-as confortáveis em relação ao sono, á fome, á sede e á higiene. Incluem a criação de um ambiente que garanta a segurança física e psicológica delas, que lhes assegure oportunidades de exploração e de construção de sentidos pessoais, que se preocupe com a forma pela qual elas estão se percebendo como sujeitos. Nesses ambientes de educação, a criança se sente cuidada. Sente que há uma preocupação com o seu bem- estar, com seus sentimentos, com suas produções, com sua auto-estima [...]. (RAMOS, 2002, p.47).
\end{abstract}

No entanto, nem sempre existiu esta visão sobre a educação infantil que se tem hoje. No Brasil, a educação da criança pequena fora do espaço doméstico e do convívio familiar iniciouse no final do século XIX, a partir de diversos contextos de demandas. Existiam duas concepções de serviços voltados para o atendimento infantil adotados no país, referindo-se assim, a duas classes sociais diferentes: a conhecida como "assistencial" para a criança pobre em instituições como as creches, salas de asilo e escolas maternais, e a do tipo "educacional", para a criança de classe média, nos jardins de infância e pré-escolas (OLIVEIRA, 1998).

Assim, enquanto os filhos das camadas médias e dominantes eram vistos como necessitando um atendimento estimulador de seu desenvolvimento afetivo e cognitivo, ás crianças mais pobres era proposto um cuidado mais voltado para a satisfação de necessidades de guarda, higiene e alimentação (OLIVEIRA, 1998, p.17). 
Id on Line Revista Multidisciplinar e de Psicologia

Id on Line Multidisciplinary and Psycology Journal

A LDB (1996) colocou a educação infantil no primeiro nível da educação básica, sendo desenvolvida em colaboração com as diferentes instâncias União, Estados, Distrito Federal e Municípios dão maior importância a implantação ou aprimoramento da pré-escola e do ensino fundamental em detrimento da creche, que por suas características apresentam um custo elevado, dificultando, assim, a participação de verbas públicas na ampliação e manutenção desse atendimento.

É importante e preciso romper com esta visão assistencialista em que as crianças vão para a creche para que os professores cuidem delas no lugar de seus pais. A escola deve ser um ambiente pedagógico, em que pelas crianças perpasse um desenvolvimento pleno. É um lugar de aproximação da cultura, da linguagem, cognição e afetividade, não priorizando apenas um ou outro elemento.

Outra questão fundamental encontra-se na importância do lúcido na formação do ser. Para isso, a escola precisa se dar conta que através do lúdico as crianças têm interessantes e concretas possibilidades de crescerem e se adaptarem ao mundo coletivo.

Em uma atividade lúdica,

\begin{abstract}
A criança começa com uma educação imaginaria, que é uma reprodução da situação real sendo brincadeira muito mais lembrança de alguma coisa que realmente aconteceu, do que uma situação imaginaria nova. A medida que a brincadeira se desenvolve, observamos um movimento em direção a realização consciente do seu propósito. Finalmente surgem as regras que irão possibilitar a divisão do trabalho e do jogo na idade escolar (VYGOTSKY, 1984, p.118).
\end{abstract}

Sobre a relação do lúcido e o meio social, compreende-se que brincando as crianças aprendem a cooperar com os companheiros, a obedecer ás regras do jogo, a respeitar os direitos dos outros, a acatar a autoridade, a assumir responsabilidades, a aceitar penalidades que lhe são impostas, a dar oportunidades aos demais, enfim, a viver em sociedade. (KISCHIMOTO, 2003).

As escolas precisam, portanto, proporcionar um espaço propicio para esse desenvolvimento, o que na realidade acontece de forma deficiente em alguns ambientes, pois um número considerável de escolas públicas funciona em condições inadequadas.

Assim, para que as crianças tenham uma boa educação, é necessário que as leis sejam cumpridas de fato para que as escolas assumam a responsabilidade para qual foram designadas. 
Id on Line Revista Multidisciplinar e de Psicoloqia

Id on Line Multidisciplinary and Psycology Journal

Um desenvolvimento satisfatório nos primeiros anos de vida de uma criança é fundamental e marcante á posteriori.

\section{Processo Histórico de Inserção do Psicólogo na Educação}

No contexto social atual, emergem de forma bem mais significativa possibilidades de atuação do psicólogo, não se justificando mais que os psicólogos restrinjam o seu fazer apenas ao contexto clinico. O cenário escolar constitui-se como uma destas possibilidades de atuação. Diga-se de passagem, é um ambiente em que a presença do psicólogo se faz essencial.

Duas áreas foram essenciais para o início da profissionalização da psicologia. Foram elas: a medicina e a educação (PEREIRA e PEREIRA NETO, 2011). Inicialmente no Brasil, quando o psicólogo foi introduzido nas escolas, estas nada mais eram se não a extensão de sua clínica.

Ele fora colocado neste espaço com a finalidade de "curar" o tão conhecido alunoproblema. Aquele que fazia o rótulo empregado e difundido na ditadura militar. Era o subversivo, aquele que se encontrava fora dos padrões do sistema, padrões estes que também eram repassados e severamente seguidos nas escolas. Problemas morais, afetivos, econômicos e outros mais, considerados inerentes á família de baixa renda, culpabilizavam-na pelo mau rendimento escolar do filho (PATTO, 1992 e 1993a). O psicólogo era um dos profissionais que também reproduzida o discurso vigente dos governantes. Ofuscando um sintonia vivido no social e alarmando os comportamentos desviantes.

Faz-se de suma relevância ressaltar que havia grupos de psicólogos que não compactuavam com a reprodução do discurso militar, no entanto, a psicologia de uma maneira mais abrangente ficou conhecida como instrumento aliado do governo.

Não apenas ao psicólogo também também era dispensado o papel de mensuração de habilidades e capacidades, aplicação e aperfeiçoamento de testes psicólogos. Toda a sua prática encontrava bases no modelo clínico de atuação.

Patto (1984) versa quando em relação ao desenvolvimento e constituição da psicólogo, que esta seria instrumento e efeito das necessidades, geradas nessa sociedade, de selecionar, orientar, adaptar e racionalizar, visando em última instância, a um aumento da produtividade. 
Nos primórdios da psicologia cientifica tal afirmação parece especialmente verdadeira em duas áreas: a psicologia do trabalho e a psicologia escolar.

Em 1962 tem-se a introdução da disciplina de psicologia escolar nos cursos de graduação em psicologia (SOARES, 1979). E na década de 1970 a criação dos conselhos de psicologia que tornaram obrigatórios os registros para as atuações como psicólogo (WECHSLER, 2001). Um fato interessante que demonstra a relação histórica do mesclar entre as duas profissões. Talvez se devesse a uma construção histórica o fato de ainda, menos expressivo atualmente, encontrar-se o fazer das duas profissões sendo confundidas.

\begin{abstract}
Durante muito tempo, a única prática do psicólogo conhecida por educadores foi centrada no modelo médico de atendimento de crianças em clínicas de psicologia. Embora a psicologia tenha se constituído enquanto profissão, no Brasil, há quase 50 anos, o psicólogo escolar não tem ainda uma posição estabelecida dentro do sistema educacional. Isso significa que ele fica alocado em secretarias de saúde e de assistência social, mas, raramente, no serviço público, dentro da própria escola (Guzzo \& cols, 2011, p.04 apud Guzzo e cols., 2007).
\end{abstract}

Retornando á psicologia escolar, quando a visão estigmatizante e assistencialista da educação perde espaço, novas práticas são repensadas, não obstante a atuação do profissional de psicologia frente a educação.

Em relação a visão que foi atribuída á psicologia, discute-se que. Já algum tempo, percebe-se força no movimento que promove a substituição gradual do enfoque no modelo clínico em detrimento do modelo pedagógico. Bem como a sobreposição do enfoque sistêmico sobre o linear, o que permite a educação novos ares e possibilidades. Respeitando as particularidades do sujeito e reconhecimento a pluralidades das ocorrências.

Para Tilmans-Ostyn e Kinoo (s/d. p.3):

O pensamento sistêmico funciona segundo um modelo circular. Isto significa que o lugar, o momento no qual situamos o início de um processo internacional, para daí deduzir uma compreensão, é totalmente arbitrário. Para iniciar a compreensão de tal processo, podemos ver outras coisas. A questão de saber quem começou, quem é a causa, não têm, portanto sentido neste modo de pensamento. 
Id on Line Revista Multidisciplinar e de Psicoloqia

Id on Line Multidisciplinary and Psycology Journal

\section{O Psicólogo na Educação a sua Relevância}

Ao se falar acerca da importância do psicólogo na educação, faz-se necessário primordialmente esclarecer em que consiste a sua prática. Uma vez inserido na escola, abre-se um leque de atividades que podem por este ser desenvolvidas. A sua pratica vai desde a escuta diferenciada; do trabalho individual, atingindo níveis de maior complexidade como o trabalho com todos os membros da escola, podendo estender-se a comunidade.

O psicólogo atua no desenvolvimento de práticas pedagógicas, bem como do trabalho com políticas públicas. A presença do psicólogo no dia-a-dia da escola constitui-se de grande necessidade para criar espaços de diálogo e reflexão a fim de contribuir para a construção de uma escola mais democrática. (Pedroza, 2003).

O Conselho Federal de Psicologia (2011) na resolução 014/00 publicada no Diário Oficial da União em 22 de dezembro de 2002, prevê como possibilidades de atuação ao psicólogo:

a) Aplicar conhecimentos psicólogos na escola, concernentes ao processo ensinoaprendizagem, em análises e intervenções psicopedagógicas; referentes ao desenvolvimento humano, ás relações interpessoais e á integração famíliacomunidade-escola, para promover o desenvolvimento integral do ser; b) analisar as relações entre os diversos segmentos do sistema de ensino e sua repercussão no processo de ensino para auxiliar na elaboração de procedimentos educacionais capazes de atender ás necessidades individuais.

Tendo em vista toda esta gama de possibilidades no que concerne ao campo da atuação do psicólogo e a importância da educação infantil como base fundamental aos estágios superiores, questiona-se o porquê de ainda não haver efetivamente a inserção deste profissional nas escolas públicas.

A rede privada de ensino há muito conta com um número expressivo de psicólogo em suas instituições. Vê-se que algo de significativo a sua prática possui, desta forma, a ausência de respostas para explicar mediante tantos fatores, que a rede pública de educação também não possa usufruir de seus serviços permanece.

Em relação a esta problemática, GUZZO e Cols (2011) afirma: 
A realidade da escola pública brasileira é muito diferente da realidade da escola privada e, é na escola pública que estudam a quase totalidade das crianças brasileiras. Com isso reproduz-se, em todos os níveis de escolarização, o despreparo e as dificuldades para que a Psicologia possa ser ferramenta de promoção do desenvolvimento de crianças e adolescentes, sem políticas públicas para o ingresso dos profissionais de Psicologia na rede pública de ensino, cada vez mais, esse cenário se distância da formação profissional e de seu campo de produção intelectual (GUZZO e Cols, 2010, p. 04 apud GUZZO e Cols 2007).

É inegável a habilidade do psicólogo para trabalhar junto á criança a formação e estruturação de sua personalidade. Habilidade esta proveniente de anos de estudos em sua formação acadêmica, bem como especializações em áreas de afinidade, o que permite uma maior complexidade de conhecimentos.

Ao psicólogo escolar cabe a função de contribuir, junto com os educadores, para a promoção da aprendizagem e do desenvolvimento das crianças, a partir de uma perspectiva mais integral do sujeito do que vem enfatizando a escola (GUZZO e Cols, 2011). Desta forma, enfatiza-se novamente a contribuição que sua atuação pode proporcionar ás crianças, não apenas a estas, mas também á escola e comunidade.

É fundamental a atuação do Psicólogo na Educação Infantil, a fim de contribuir para o desenvolvimento de recursos da personalidade das crianças, visando á formação de indivíduos autônomos, críticos e solidários (Andrada, 2005).

O CFP - Conselho Federal de Psicologia - juntamente com o apoio do Conselho Federal de Serviço Social (CFESS) lançou para aprovação em 2007 o Projeto de lei (PLC 60/2007) que visa a prestação de serviços tanto do profissional de psicologia, quanto de assistência social nas escolas públicas de educação básica (POL, 2011).

No projeto de lei de número 3688/00 o congresso nacional declarou que: Art. $1^{\circ}$ - O Poder Público deverá assegurar atendimento por psicólogo e assistentes sociais a alunos das escolas públicas de educação básica que dele necessitarem.

Refletindo acerca da iniciativa mencionada, destaca-se que embora psicólogo ou não se deve buscar garantir que a educação infantil pública receba a atenção que lhe deve ser dispensada. Não abrindo, pois, espaço para que em um futuro próximo seja necessário a intervenção de medidas paliativas e emergenciais para contornar problemas que poderiam ter sido mais bem articulados em sua origem; em sua base. 
Id on Line Revista Multidisciplinar e de Psicologia

Id on Line Multidisciplinary and Psycology Journal

\section{Considerações Finais}

A partir das considerações aqui elencadas, se reconhece a necessidade de que discussões como esta sejam mais frequentemente debatidas, não resumindo-se apenas ao campo da ideologia, toda via enveredando-se para plano da ação. É preciso que as prioridades sejam seguidas e cumpridas, haja vista que educação não é brincadeira, e muito já se foi negligenciado em detrimento de práticas paliativas.

Em relação á classe de psicólogos estes por sua vez devem atentar para a necessidade de unirem-se de maneira mais incisiva para promover seu ingresso no ambiente escolar. Ele já atua neste contexto, porém, embora existam inúmeros trabalhos voltados para atuação da psicologia na escola, a rede pública de educação ainda não pode contar com esta contribuição. Com esta parceria que por demais contribuiria para o bom desenvolvimento das relações internas e com a comunidade.

O reconhecimento do próprio fazer também é um determinante, afim de que o psicólogo se reconheça neste espaço e possa promover mudanças; transformações. Promover autonomia e consequentemente crescimento. Não se pode esperar que as mudanças ocorram de cima para baixo, e sim focar na elaboração de políticas públicas que promovam ações mais efetivas no que concerne a psicologia e sua relação com a escola; e com a educação infantil.

Deixa-se aqui registrada uma significativa preocupação com os rumos noda educação infantil pública e o papel do psicólogo neste processo. A busca no oferecimento de melhor assessoria á educação já foi iniciada, espera-se que ela continue e produza conquistas mais concretas. Permitindo que o acesso a um trabalho tão belo, como é o da psicologia, possa chegar com maior intensidade e qualidade aos que dela necessitam.

\section{Referências}

ANDRADA, Edla Grisard Caldeira. Psicologia escolar em educação infantil :Reflexões de uma atuação. Novos Paradigmas na Prática do Psicólogo Escolar, 2005.

ANTUNES, Celso. Novas maneiras de ensinar, novas formas de aprender. Porto Alegre: Artmed, 2002. 
Id on Line Revista Multidisciplinar e de Psicologia

Id on Line Multidisciplinary and Psycology Journal

ARIÉS, Philippe. História social da criança e da família. 2. ed. Rio de Janeiro: LTC, 2006.

BEE, Helen. A criança em desenvolvimento. 9. ed. Porto Alegre: Artmed, 2003.

BRASIL. Lei $\mathrm{n}^{\circ}$ 9.394, de 20 de dezembro de 1996. Estabelece diretrizes e bases da educação nacional. Diário Oficial [da] República Federativa do Brasil, Brasília, DF, 23 dez. 1996.

CAMARA DE DEPUTADOS. PL 3688/00. Disponível em:

http://www2.camara.gov.br/agencia /noticias/ PROJETO-PREVE-PSICOLOGO-EASSISTENTE NA ESCOLA html. Acesso 03 de outubro de 2016.

CFP. Conselho Federal de Psicologia. Resolução CPF $\mathbf{n}^{0}$ 014/00. Diário Oficial da União (D.O.U): Brasília-DF em 22 de dez. 2000.

CÓRIA-SABINI, Maria Aparecida. Psicologia do desenvolvimento. São Paulo, SP: Ática, 1993.

GUZZO, Raquel S. L. et al. Psicologia e educação no Brasil: uma visão da história e possibilidades nessa relação. Psicologia Teoria e Pesquisa., Brasília, v. 26, n. spe, 2010. Disponível em: http://www.scielo.br/scielo.php?script=sci arttext\&pid= Acesso em $13 \mathrm{de}$ setembro de 2016.

KISCHIMOTO, Tizuko Morchida. O Jogo e a Educação Infantil. São Paulo: Pioneira, 2003.

MINAYO, Maria Cecilia de Souza. O desafio do conhecimento: pesquisa qualitativa em saúde. 10. Ed. São Paulo: Hucitec, 2007.

MOREIRA, Paulo Roberto. Psicologia da educação. Interação e identidade $-2^{\circ}$ Ed.- São Paulo: FTD, 1996.

OLIVEIRA, Marta Kohi de. Vygotsky: aprendizagem e desenvolvimento- um processo sócio-histórico. São Paulo: Scipione, 1998.

PATTO, M. H. S. Psicologia e Ideologia: uma introdução crítica a psicologia escolar. São Paulo: T. A. Queiroz, 1984.

PATTO, M.H.S.(Org.) Introdução a psicologia escolar. $2^{\circ}$ ed., $4^{a}$ reimpressão. São Paulo: T.A. Queiroz, 1993a.

A família pobre e a escola pública: anotações sobre um desencontro. Psicologia USP, São Paulo, 3 (1/2), p. 107-121,1992.

PEREIRA, Fernanda Martins; PEREIRA NETO, André. O psicólogo no Brasil: notas sobre o seu processo de profissionalização. Disponível em: http://www.scielo.br/scielo.php?pid=S1413. Acesso em 13 de setembro de 2016. 
PEDROZA, R.L.S. A Psicologia na formação do professor: uma pesquisa sobre o desenvolvimento pessoal de professores do Ensino Fundamental. Tese de Doutorado, Universidade de Brasília, Brasília, (2003).

POL- Psicologia Online. Disponível em http://www.scielo.br/scielo.php?pid. Acesso em 15 de outubro de 2011.

RICHARDSON, Roberto Jarry. Pesquisa Social: métodos e técnicas/ Roberto Richardson Jarry; colaboradores José Algusto de Sousa Peres...(et,al.) - São Paulo: Atlas, 1999.

RAMOS, Zilma de Oliveira. Educação Infantil: Fundamentos e Métodos. São Paulo: Cortez, 2002.

SOARES, A. R. A psicologia no Brasil. (1979). Em conselho Federal de Psicologia. Psicologia ciência e profissão. (Edição Especial), n. 0, 09-59.

TILMANS-OSTYN, E. \& KINOO (s/d). Algunos aportes de la terapia familiar a la práctica médica cotidiana. Hospital: Herminio Valdizan. Departamento de Psiquiatria Familiar.

WECHSLER, Solange. (org.) Psicologia Escolar: pesquisas, formação, prática. CampinasSP: Editora Alínea, 2001.

VYGOTSKY, Liev Semionovich. A formação social da mente. $6^{\circ}$ ed. São Paulo: Martins Fontes, 1984.

Como citar este artigo (Formato ABNT):

SILVANA, F.S.S.; OLIVEIRA, G.F. Psicologia e Educação Infantil: desafios atuais. Id on Line Revista Multidisciplinar e de Psicologia, Janeiro de 2017, vol.10, n.33, Supl 2. p. 282-293. ISSN: 1981-1179.

Recebido: $22 / 12 / 2016$

Aceito: 19/01/2017 